\title{
WikiLeaks, Anarchism and Technologies of Dissent
}

\begin{abstract}
WikiLeaks is a controversial organisation that attracts polarised responses. This is not unexpected given its key objective of exposing the secrets and social control ambitions of the powerful. While its supporters laud its pursuit of an informational commons, its detractors condemn its anti-social character, its megalomania - and its anarchism. It is the latter that particularly interests us here. This paper treats the 'charge' of anarchism seriously, however, giving it the analytical attention it warrants. It does this by first identifying those characteristics of the organisation that would render it anarchist, and then to conceptualise what this anarchism means. It highlights two important elements of the WikiLeaks story: the anarchical character of the technologies it utilises to foment its dissent; and the anarchical ethos of the organisation's radical politics. We conclude by also considering the tensions and contradictions in WikiLeaks that temper both its anarchism and its social change objectives.
\end{abstract}

\section{INTRODUCTION}

WikiLeaks emerged on the global political stage in earnest in 2010 when it leaked a large number of secret government documents and made them available through its Internet site. The response was loud and immediate, and either highly condemnatory or highly congratulatory. Since its inception several years ago, WikiLeaks has aimed at the direct exposure of the secrets that underpin statist institutions' social control ambitions. As the organisation's 'editor-in-chief', Julian Assange charged that "a world wide movement of mass leaking is the most cost effective political intervention" for challenging a widespread "governance by conspiracy and fear" (in Gellman 2010). The reaction, from government quarters at least, was unsurprisingly strident and disparaging. Among the general public, however, the reaction was more mixed; ranging from the appalled condemnation some shared with governments, to those who lauded the democratic commitment to information transparency that the organisation seemingly championed. Many of WikiLeaks' detractors framed their criticism in terms of the organisation's criminality, its wilful disregard for national and global security, its megalomaniacal character - and its anarchism. Indeed, a 
spokesperson for the US State Department, P. J. Crowley, intent on fomenting a negative characterisation of WikiLeaks, declared that Assange "is not a journalist" or "a whistleblower"; he is "a political actor ... [with] a political agenda ... an anarchist" (Indianexpress.com 2010).

As general criticism the charge of anarchism is often used loosely and pejoratively, meant to signify the organisation's anti-social temperament, and its preparedness to sully the norms and practices of a decent social order. This paper is interested in WikiLeaks characterisation as anarchist but treats the charge more substantively than is usually the intent of these general critics. In this paper we thus seek to identify those characteristics of the organisation that would render it anarchist and then to conceptualise what its anarchism means.

The story we tell in this paper also has important spatial dimensions. This is because, first, it takes place within a new technological and cyberspatial landscape that has helped (re)shape the contours of contemporary lived experience, with the Internet - a technology that compresses space and time in novels ways - central to this story. As Dodge and Kitchin (2001:xi) observe: information and communication technologies and the cyberspace environment they inhabit are today "radically restructuring the materiality and spatiality of space and ... and changing the way we live our lives ... regardless of whether we actively use them". While the nature, scope and implications of this 're-shaping' is highly contested, both within anarchist thought and society more broadly, most agree that these technologies have shaped the contours of economic, social and political life in significant ways - as the processes of globalisation well illustrate. Today's flexible accumulation regime - enabled by the increasing mobility of capital flows across the globe - necessarily alters "the relationship between the territoriality of political power and the spatiality of capital 
accumulation" (Harvey in Schouten 2008:1). WikiLeaks seeks to mount a counterresponse to the forces of neo-liberal globalisation and the re-worked geographies of inequality and domination that occur in its name. Since the new technologies are an important driver of today's globalised landscape, 'hacker' organisations such as WikiLeaks inject their struggle both through the use of the new technologies, and against the kind of world they have more recently enabled.

There is another reason why the spatial dimension is important to the anarchist story we tell here. As Crampton (2003: 1-2) points out, "[s]ocial life is inherently spatial ... we live in, open up, shape, and are shaped by, spaces and places". Anarchists observe that many of these spaces are colonised by dominant powers that set out to out to shape these spaces in ways that reinforce their domination. Anarchism's emancipatory focus is hence on the creation of decentralised "free spaces" that challenge prevailing hierarchical and centralised arrangements (see Breitbart 2009). Since anarchists are fundamentally concerned with "the qualities of life of particular places", David Harvey observes that "the tradition in geography of radicalism" is necessarily anarchist (in Williams 2007).

As we discuss, the new technologies offer opportunity for counterappropriation for emancipatory ends, and this is precisely the opportunity WikiLeaks' eyes off. This paper thus focuses on two key components of the telling of the WikiLeaks story through an anarchist prism: the anarchical elements of the computer mediated technologies that are utilised, particularly the Internet, and the anarchical ethos of the organisation's politics. We argue that the interrelated character of these two components is important to understanding the nature of the organisation's anarchical temperament. 
Anarchism is, of course, a multifaceted and wide-ranging ideology with "a broad back"; boasting many well know actors and theorists from a range of political backgrounds and positions (see Rocker 1938; Guerin 1970; Marshall 1993; Kinna 2005; Curran 2006; Gordon 2007a). Its political philosophy has seldom commanded the respect of the other 'major' ideologies such as liberalism and Marxism, however, with its oeuvre often dismissed as fanciful and its views treated with considerable suspicion, as the current treatment of WikiLeaks highlights. While a robust discussion of anarchism is outside the scope of this paper, and while the identification of its core values runs the risk of simplifying what is in actuality a complex political composition, some isolation of key principles is necessary at the outset in order to proceed with this paper's narrative. The principles of liberty and autonomy are central to anarchism, and since the state is viewed as the acme of centralised and institutionalised authority, anarchists, by and large, resist it. The tenor of this resistance helps describe the many different varieties and expressions of anarchism. Anarchists are alert to the forces that would trample freedom and agency particularly the forces of institutional mediation, centralisation and hierarchy. Their anti-authoritarianism (which assumes many forms), and their championing of a necessary correspondence between means and ends, is thus directed towards protecting their animating principles.

Throughout the paper we also distinguish between the terms 'anarchist' and 'anarchical'. This reflects our sympathies for some of the more recent scholarship on contemporary anarchism which, generally, distinguishes some actors' robust ideological embrace of anarchism from those inspired by the force of its analyses and animating principles. For example, Neal (1997) distinguishes between "small a" and "capital A" (or highly ideological) anarchism, a distinction that Graeber (2002) also 
embraces in part to support his characterisation of "the new anarchists" in the antiglobalisation movement. Utilising similarly conceptualised distinctions, Epstein (2001) talks of anarchism per se and anarchist sensibilities, while Curran (2006) theorises a "post-ideological" anarchism, which refers to the looser and less doctrinal embrace of anarchist ideas and strategies by actors who do not necessarily identify as, in effect, "card-carrying" anarchists.

To discuss WikiLeaks' relationship to anarchism, the paper is divided into three main sections. The first section discusses the theoretical and historical background that informs the WikiLeaks story in important ways. Here it first discusses the anarchical Internet and the emergence of the anarchical hacker cultures that helped shape it; hackers that, in the face of the technology's eventual commodification, then sought to counter-appropriate it. The second section charts the specific WikiLeaks story, situating it within this theoretical and historical background, before tracing its specific brand of cyber-hacking and the principles and motivations that drive its formation, its organisational shape and its subsequent politics. While this paper is an analysis of the anarchical character of WikiLeaks, due to the towering influence Julian Assange exerts over the formation and trajectory of the organisation, we necessarily pay close attention to his ideas and how they impact upon it. Third, the paper considers WikiLeaks' anarchism more directly, focusing on some of the elements central to an anarchist praxis and that in turn characterise key aspects of the organisation's ethos and identity. Finally, the discussion concludes with a critique of WikiLeaks' more recent praxis and the implications this has for its anarchical ethos more broadly.

\section{TECHNOLOGY AND DISSENT}


Technology has long shaped the fabric of social life. As a key driver of social change, human history is replete with instances of the social transformations driven by technological developments. Computer mediated technologies, and their operation in and creation of a novel spatial landscape, are indeed new and compelling. But technological developments do not emerge in a social or political vacuum, nor is technology neutral. Since their shape, scope and utility is determined by existing social forces technologies "are not merely aids to human activity, but also powerful forces acting to reshape that activity and its meaning" (Winner 1985:11).

With technology such a powerful force, it is no surprise that the anarchist's view of it is cautious and circumspect. On the one hand, some anarchists celebrate technology's capacity to improve people's lot and/or advance libertarian or democratic principles - as in the case of an anarchical WikiLeaks. On the other hand, they are also alert to its potential for social control. Since technology is both socially produced and socially transformative, a distinction is often drawn between the benefits of technology per se, and its power relations - that is, the use to which it is put, the manner and focus of its distribution, and the social and political impacts of its commodification. This is similar to a position Gordon (2009: 492) attributes to what he calls 'Promethean' anticapitalists, like Proudhon, who argue it is important to distinguish between the "essence of the technology" which, in its capacity to enhance freedom and creativity, can be seen as "intrinsically positive"; and the "effects of the technology" which, particularly under capitalist power relations, can be viewed as inherently suspect. But the history of technology is also one of its capacity for utilisation in ways that may not have been originally intended. The origins of the Internet, as we discuss below, echo a strong libertarian ethos, even as this ethos was rapidly diluted by its subsequent commodification. 
Three interrelated characteristics are important to understanding WikiLeaks anarchical engagement with these new technologies. First, while some technologies are viewed as inherently ideological in their capacity to reinforce prevailing power relations, others incorporate design principles that offer the capacity for counterappropriation in the service of more emancipatory ends. The Internet is one such 'anarchical' design technology, particularly through its capacity to generate an informational commons and hence its potential to invigorate democracy (see Crang 2000: 307-317). Yet, as we discuss below, this enthusiasm is tempered by the fact that the actualisation of this libertarian potential is reliant on the physical materialisation of a critical public in public spaces (for instance, in the act of protest). Second, while the Internet has also become increasingly centralised - particularly through a centrally organised domain name system that emerged during the Internet's early commercialisation and privatisation (see Mueller et al 2007) - its design continues to enable avenues of utilisation that resonate some anarchist values. Third, through a combination of the first two elements, a form of anarchical politics is generated, as exemplified most directly in hacker culture. The dynamic nature of these characteristics is important to conceptualising WikiLeaks as anarchical - particularly through the congruence it can signify between means and ends.

\section{Anarchists, Technology and the Internet}

Since there is no overarching agreement on technology among anarchists, WikiLeaks' embrace of the democratic capacity of new communication technologies is not necessarily a commitment shared by all. Some anarchists, for example, harbour a staunch opposition to what they consider the unmitigated ravages of technology. This reflects a debate about technology that has, in some form or other, long occupied 
anarchists' political repertoire. Anarchist positions on technology are hence conceptualised in a number of often very divergent ways. These positions share, however, an objection to its power relations - regardless of the socio-economic system in which these technologies may be embedded. The claim here is that technologies do not emerge freely and neutrally; rather they are selected or utilised in response to prevailing social relations and ideological objectives. Evoking Foucault's panopticon, Gordon (2009:496) notes that "[a] society biased toward hierarchy and capitalism generates the entirely rational impetus for ... surveillance". For anarchists, some technologies are hence intrinsically ideological. These technologies - such as nuclear power - are viewed as inherently state-centred and centralising since their operation and control require an extensive and hierarchically organised state apparatus (see Winner 1985:29-37; Gordon 2009:500).

This general suspicion of technologies' power relations is probably a position that WikiLeaks shares, as evidenced in particular by its determination to prevent a democratic cyber space or commons from commercial enclosure. But as a consumer of these technologies, WikiLeaks would not share some anarchists' resolute opposition to all technologies - indeed, to technologism as a practice and ideology. Anarcho-primitivists or "anti-civilizationists", such as John Zerzan, for example, oppose the technology-enabled evolution toward civilization, or "symbolic culture", and view technology as the major tool in the state's social control armoury (Zerzan 1994). Since technology is heavily implicated in the project of domination and control, anarcho-primitivists and their sympathisers urge that it be opposed in its entirety (see Green Anarchy Collective 2004). This form of technology needs to be clearly distinguished from tools, however: tools help achieve set tasks while the technology project is a fundamentally oppressive one. 
Other anarchists take a less deterministic approach arguing for "human-scale" technologies in the service of broader, rather than narrowly commodified, social goals. Prominent eco-anarchist and social ecologist, Murray Bookchin, for example, finds much potential in technology. He calls, however, for appropriately scaled and ecologically sound forms of technology - what he labels a "libertarian technics" (1991). Following Lewis Mumford, Bookchin contrasts libertarian technologies (fundamentally egalitarian) to authoritarian ones (fundamentally hegemonic). For Bookchin - and here WikiLeaks would largely concur - it is thus not technology per se that has driven social and ecological ruin - rather it is a technics in the hands of a hierarchical elite that explains its destructive thrust.

\section{An Anarchical Internet}

Whether welcomed or otherwise, information, communication and computer technologies are now a central feature of contemporary life, and the Internet sits at their core. For many (particularly in the West), the Internet can be viewed as the very "fabric of our lives" and communication technologies "the present-day equivalent of electricity in the industrial era" (Castells 2001:1). As a highly sophisticated global communication network, particularly through the interconnected admission it provides to a more accessible informational commons, the Internet has transformed the structures and processes through which economies, politics and society function. Whether this means that it has changed the fundamental nature, as opposed to expression, of unequal power relations is another matter altogether.

The Internet may today be a highly commodified tool of the global marketplace, but it was not always so, with the Internet's libertarian history an interesting one. Before its commercial potential was corralled in earnest, its 
development exhibited characteristics that were surprisingly libertarian or anarchic. Its underpinning values of creativity and collaboration within a public knowledge space drove a rush of originality, imagination and innovation that produced some quite remarkable software inventions. Abbate (1999:2-3) traces the Internet's story, noting that it is not one "of a few heroic inventors" but rather one of "collaboration and conflict among a remarkable variety of players" who were motivated - at least originally - by respect for ideas and creativity rather than profitability and individual glory. The Internet emerged as part of "a culture which had no professional secrets, in which co-operative effort was the order of the day and in which the only judgment worth bothering about was that of one's peers" (Naughton 2000:196). While key individuals did play an important role in its rapid development, its early days were characterised by a "knowledge ecology" constituted of active participants playing their part in a creative technological mosaic. It is for these reasons that the Internet's libertarian development has been conceived of as a "gift economy" or informational commons that eschews hierarchalism by sharing and equalising participation, innovation and knowledge creation. It is elements of this free 'gifting' of information to all peoples that WikiLeaks essentially evokes.

The Internet began its evolution in the 1960s in support of a decidedly nonanarchical enterprise - essentially as a resource that would strengthen US strategic capacity during the Cold War. Driven by the military objectives of the US Defence Department's Advanced Research Project Agency, the Internet emerged at "the unlikely intersection of big science, military research and libertarian culture" (Castells 2001:17). This was a creative communitarian network driven by a libertarian ethos that valued creative pursuits and knowledge creation for their intrinsic rather than instrumental ends (see Abbate 1999; Castells 2001). It is within hacker culture, 
however, that the Internet's libertarian and anarchical ethos is most directly invoked (Jordan 2008). Today, the term hacker has pejorative, indeed criminally sinister, overtones. However, its original meaning was very different. According to Jordan (2002:120), the term 'hack' originally signified a creative user of new technology, and hackers were renowned for their pursuit of innovation within a collaborative technoculture that valued, and shared, creative invention and knowledge generation. There is also a distinction between 'hackers' and 'crackers', the latter more generally understood as those who enjoyed crippling systems for personal or criminal gain. As Saco (2002:28 n.22) points out, the term 'crackers' "was actually invented by hackers themselves to distinguish between, on the one hand, their own benign practices of breaking into computer systems for the intellectual challenges they pose, and, on the other hand, 'cracking' into systems for malicious and or/illegal purposes”. Of course, WikiLeaks contains elements of both categories since much of what they do is constituted as illegal. For Jordan (2008:14) the important point is that hackers "resist being technologically determined themselves and [seek] to reform technologies so there are new determinations". For WikiLeaks this translates to hacking (and where necessary, cracking) in order to displace hegemonic determinations for more emancipatory ones. Assange claims to have eyed this potential long ago and recently reaffirmed his faith in the libertarian potential of these technologies, contending that while governments and patronage networks "deepened their advantages", it also "began to appear possible that what secret riots, opposition groups, human rights gurus and electoral reform has always struggled to achieve, we could actually bring about with science" (in Welch 2011). To this degree, "hacktivism" - including WikiLeaks' version of it - is motivated by a libertarian ethos that views the "free 
flows of information, securely accessible to all" as "the highest principle" (Jordan 2002:121).

Another commentator conceived of the hacker culture as the "great unwashed" or the "homebrewers", highlighting the anarchic character of these geekish outsiders" relationship with the technology (Naughton 2000). At first these outsiders "gazed enviously" at the techno-elites "much as poor kids in black neighbourhoods might peer over the wall at rich kinds enjoying the facilities of an expensive tennis training complex" (Naughton 2000:185). However, they soon appreciated and drove the Internet's 'anarchy'. The new technology's then absence of more centralised hierarchical control rendered it open and egalitarian, and through its admittance of all comers, turned the inclusion/exclusion dynamic on its head. The original techno-elite community may have been "a disciplined, orderly, relatively homogenous" one, but its hacker "descendants" were instead "brash and undisciplined and ... beyond anyone's control" (Naughton 2000:192). This became an entry point for WikiLeaks' early hacker operatives, an outfit with an emerging identity as "electronic libertarians" (Manne 2011) - as discussed in the next section.

The increasing commercialisation of the technology drove a fierce determination to maintain its essentially libertarian spirit - transforming hacking into not only a creative but also a highly political act. It was to be, to some degree, a David and Goliath struggle between anarchic hacker "outsiders" against the institutional might of the market and the state. Early fellow hackers such as Stallman and Torvald began the resistance to the technology's commodification by creating processes to undermine it. They started an organisation called The Free Software Movement before launching a "copyleft"' licensing system in the 1980s to resist the commodification 
trend, particularly as enacted through copyrighting (see Free Software Foundation n.d).

By the 1990s the Internet explosion was well and truly underway, driven by the rapid growth in ownership of personal computers, the proliferation of protocol software, and in particular, the launching of the World Wide Web as a more effective multi-media interface. A key player in the World Wide Web's creation, Tim BernersLee, was inspired by the 1974 Computer Lib hacker "manifesto" (see Abbate 1999:214-20). This manifesto was essentially a call to arms for the democratisation and free dissemination of, and participation in, computer technologies for ordinary people, shifting them from the confines of what was considered at the time to be a technological elite or "computer priesthood". The WWW launched an extensive array of diverse virtual communities, not all of whom were dedicated to the hacker's libertarian ethos and its commitment to free participation, contribution and access. Yet they shared, on some level at least, an allegiance to open and free communicative practices - to what can effectively be understood as a kind of electronic public sphere that enabled the virtual practice of global free speech.

\section{The Limits and Promises of an Anarchical Internet}

These libertarian impulses were relatively short-lived, however, quickly countermanded by more commercial enterprises that have, for some, reduced the Internet to a "zero institution" (Dean 2003). As Sassen observes, since digital space is "embedded" in the dominant socio-cultural and economic systems of lived experience, we "cannot take the distributed power and hence the democratising potential of digital networks" as inevitable (2002, 367). Gilbert et al (2008:915) agree, pointing out that access to the Internet is "embedded in and reinforces broader, social, 
economic, and political inequalities". Reinforcing this, anarchist Hakim Bey regrets his original enthusiasm for the technology, observing that as early as the mid 1990s, the Internet "had succeeded in burying the 'anarchic potential' of the Net" under the onslaught of a "triumphalist, evanescent, aesthetically bankrupt, monocultural [and] violent" global capitalism (2003, xi). It is for these reasons that many are now circumspect about the Internet's emancipatory potential, highlighting the fact that the Internet is a "social product, interwoven with relations of class, race and gender" and hence not "inherently emancipatory" (Warf 2001, 6). Instead, since the Internet "is deeply conditioned by where one is" $(2001,16)$, cyberspace itself is not only closely tied to the "very real spaces of class and power" but also replicates these categories and their place-based realities $(2001,15)$.

There are some important elements to this uneven and unequal geography of the Internet, elements that in turn become important in understanding both the trajectory and impacts of WikiLeaks, as discussed in our conclusions. First, it is clear that access to these technologies is unevenly and unequally dispersed. While their spread is rapidly increasing, the developed world clearly has readier access than the developing; and even in the developed world, access is circumscribed by gender, class, identity and locality (see Sassen 2002; Gilbert et al 2008). Second, the increasing privatised appropriation of digital space circumscribes its use and form, with much consumption of the new technologies concentrated on new social medias, electronic marketplaces and various entertainments (see Zook and Graham 2007; Christensen 2011). Finally, while Crampton notes that cyberspace is today "an extraordinarily open site of contestation" (2003: 3), the 'on-the-ground' material plane is nonetheless critical to effecting social change (see also Springer 2011). After all, "[a]ll the web communications in the world would not have nearly shut down the 
Seattle meeting of the World Trade Organisation or destroyed the Genoa talks. But people in the streets did" (Mitchell 2003b: 147; see also Wainwright and Kim 2008). Diani (2001: 126) making a similar observation, writes that 'virtual networks operate at their best when they are backed by real social linkages in specifically localised communities'; while others highlight the Internet's reinforcement of 'traditional' protest activities rather than their substitution (see Pickerill 2003).

One needs to be cautious, however, in dismissing the Internet's libertarian potential altogether. Despite very real limitations, these technologies continue to offer possibilities that render them useful armoury in the social change project. Indeed, one of the anarchical hacker's goals remains to remake these possibilities for more emancipatory ends. Aside from information leaks, the Internet has played an important role in facilitating political protest across the globe (see Wainwright and Kim 2008; Meek 2011; Curran 2006). As Sassen observes, while the new technologies may manifest as a "major new theatre of capital accumulation", at the same time "civil society - in all its various incarnations - is also an increasingly energetic presence in cyberspace" $(2002,381)$. It is in this spirit that WikiLeaks utilises the Internet. It recognises that while, on their own, the new technologies do not automatically generate more open, democratic practices, it is the use to which they are put that gives them their normative and political form. As Bohman points out, the Internet "becomes a public sphere only through agents who engage in reflexive and democratic activity"; its political character is thus determined by "the mediation of agency" rather than simply "on the technology", even as the capacity of the technology is important $(2004: 140,139)$. In short, the Internet is only an open and "public sphere ... if agents make it so" (2004:132). The tools of hacktivism are 
utilised, after all, by a broad range of actors inspired by a broad range of ideological positions and motives.

Hacker resisters, such as WikiLeaks, are hence determined to remain 'an energetic presence in cyberspace', devoted to protecting a newfound cyberspace commons from a rapidly corralling entrepreneurial market and political state. Through "the mediation of agency" WikiLeaks' actors remain committed to the utilisation of available technologies to re-animate the public sphere. Essentially WikiLeaks' champions "a recurring idea in hacker culture" - that of "a digital safe haven that is anonymous, massively collaborative and highly resistant to attack or penetration by intelligence services" (in Gellman 2010). In so doing, WikiLeaks "has made novel use of an alphabet soup of existing geek tools" (Gellman 2010), putting them in the service of global free speech and the openness and transparency that nourishes it. Armed with a sophisticated command of the new technologies, and inspired by the dissent that they enabled, the WikiLeaks enterprise was launched in earnest. Before we consider how effectively it has achieved its goals, we first tell the WikiLeaks story.

\section{THE WIKILEAKS STORY}

Until recently, WikiLeaks was a well-respected, yet small and relatively uninfluential, document-leaking organisation. In 2010, this innocuous image was forever shattered with the release of the now infamous "Collateral Murder" video bringing WikiLeaks global attention. This was quickly followed by two massive document dumps centred around the US-led wars in Iraq and Afghanistan and a slow leak of US State Department diplomatic cables. As a result of this tumult, WikiLeaks now stands at the centre of an imminent global culture war which, broadly speaking, can be divided into 
two groups. On the one hand are the forces of state secrecy and institutional power. These forces - exemplified most prominently by the US government - defend the pragmatic necessity of state secrecy in order to preserve the integrity of national security. On the other stands WikiLeaks and its allies, who argue that the political agenda should not be dictated from above and that a priori state secrecy is antithetical to the idea of a free and open society. As this analysis will show, WikiLeaks seeks, more concretely, the actualisation of the promises of the anarchical Internet and hacker culture explored above. In spite of Foucault's (1980: 98) reconceptualisation of power as "something that circulates" in a ubiquitous, but negotiated, fashion amongst relatively situated actors, it is impossible to deny that some have more power than others in the historically specific epoch of late capitalism and that this power, in multifarious dimensions, leads to the domination of some over others (see Lukes 2005). By utilising advanced technology in the service of leaking, WikiLeaks aims to unravel the 'conspiracies' of the powerful and in their wake, approximate the anarchical vision of a decentred, non-hierarchical and directly democratic society.

This section begins by exploring WikiLeaks' foundations, particularly the way it has presented itself as a reformist, non-profit media organisation. Given the overriding influence that Julian Assange exerts over the organisation - in both its everyday functioning and intellectual legitimation - and the considerable body of written and verbal material he provides, we then necessarily pay particular attention to the ideas of WikiLeaks' 'editor-in-chief'. Throughout, we highlight two keys ideas 'conspiratorial government' and 'transparency activism' - which most heavily influenced Assange's application of 'hacktivism', the creation of WikiLeaks and the shaping of the organisation's overall anarchical vision. 


\section{Wikileaks as Liberal Reformism}

To some degree, the 'official' WikiLeaks' story is one typical of a reformist, liberal organisation. It is an organisation dedicated, through leaking, to bringing significant news and information to public attention. By doing this, WikiLeaks claims it is able "to publish original source material alongside... news stories" in the hope that "readers and historians alike can see evidence of the truth" (WikiLeaks 2011). Having survived "widespread persecution" at the hands of legal and political institutions that seek to silence the organisation and the journalists and sources associated with it, WikiLeaks continues to pursue "[t]he broader principles on which our work is based", which are "the defence of freedom of speech and media publishing, the improvement of our common historical record and the support of the rights of all people to create new history" (WikiLeaks 2011).

WikiLeaks initially sought to be an "uncensorable version of Wikipedia for untraceable mass document leaking and analysis" (CBC News 2007). Though it is no longer based on a user-contribution model ('wiki' - a point that will be returned to later), WikiLeaks differs from more 'traditional', offline leaking organisations in that it is based primarily online, offering electronic drop boxes reinforced by advanced cryptographic information technology that serves to protect source anonymity. By making use of such technologies, the organisation can handle sensitive material from the upper echelons of government and corporations and disseminate it accurately. After receiving information, WikiLeaks' journalists evaluate it, verify the material and write a news piece depicting its relevance to society (WikiLeaks 2011). This coalesces with the liberal notion that transparency breeds accountability and reduces corruption, which in turn, strengthens democracy within all of society's institutions, including corporations, governments and other organisations. As Assange opined in a 
piece for The Australian, democracies need a strong media, of which WikiLeaks is a part, to facilitate open and honest government (Assange 2010a).

\section{Transparency Activism and Conspiratorial Government}

The utilisation of modern communications technology in the pursuit of transparency is central to the praxis and significance of WikiLeaks. It is an organisation founded on "getting information through", but "with a moral dimension... the goal is justice ... the method is transparency" (Assange cited in Pilger 2011). This didactic position is exemplified by the recent actions taken by WikiLeaks, including the mass leaking of US State Department documentation, or the posting and distribution of censored videos in an attempt to subvert the 'Great Firewall of China'. Indeed, in a recent interview Assange describes 'transparency activism' as the modus operandi behind WikiLeaks:

We have clearly stated motives... We are transparency activists who understand that transparent government tends to produce just government. And that is our sort of modus operandi behind our whole organization, is [sic] to get out suppressed information into the public, where the press and the public and our nation's politics can work on it to produce better outcomes (Assange 2010b).

Immediately, one is able to detect the reformist character of the language central to the public propagation of WikiLeaks. In and of itself, the notion of transparency activism appears to aim at little more than the realisation of the liberal notion of accountable, transparent government, actualised through political activity and pressure in the realm of civil society. Clearly, this falls short of an anarchist desire for a stateless society. Furthermore, the very notion of 'just government' is, to an 
anarchist, oxymoronic. This contradiction reveals the significance of the key distinction, made above, between an 'anarchist' and 'anarchical' political praxis; and our claim that WikiLeaks is an exponent of the latter. It also reveals the tension between the reformist means and the revolutionary ends of WikiLeaks. Nonetheless, transparency activism links to Assange's more radical conceptualisation of 'conspiratorial government' insofar as it is critical to unravelling conspiracies and bringing down authoritarian organisations.

In a now famous blog, State and Terrorist Conspiracies, Assange (2006a:2) claims that the "inner workings of authoritarian regimes" reveal "conspiratorial interactions" as the primary methodology "behind maintaining or strengthening authoritarian power" (Assange 2006a:2). Here, conspiracies should not be understood as surreptitious, evil plans, but rather, as relatively banal, everyday occurrences. A conspiracy merely refers to a general network of individuals who act in unison by concealing their association and communicative practices from outsiders. In this sense, a conspiracy could be something vivid, like a coalition looking to begin a war, state actors attempting to consolidate power, or the everyday banalities and deceptions that form inter-state diplomacy.

Authoritarian regimes are considered to be inherently conspiratorial as they seek to maintain power through communication practices intended to deceive. Through their perpetual propagation of conspiracies, they give "rise to forces which oppose them by pushing against the individual and collective will to freedom, truth and self realisation. Plans which assist authoritarian rule, once discovered, induce resistance. Hence these plans are concealed by successful authoritarian powers" (Assange 2006a:2). As Assange argues in Conspiracy as Governance (2006b:2), 
"[t]his collaborative secrecy, working to the detriment of a population, is enough to define their behaviour as conspiratorial". In order to challenge the conspiracy of authoritarian governance, it is necessary to counter the capacity for conspirators to communicate in a concealed manner. When "conspiratorial power" is negated, information no longer flows between conspirators, and the conspiracy dissipates.

Additionally, the emergence of new technology enables some to "outconspire" others. Assange argues that the revolutions in literacy and communications technology have empowered conspirators with new means to conspire in that they have allowed for an increase in the "speed of accuracy of their interactions and thereby the maximum size" that a conspiracy may achieve before breaking down (Assange 2006b:5). However, though modern communications technologies increase the capacity for mendacious organisations to maintain conspiracies, through counterappropriation activities such as those employed by WikiLeaks they also provide potential for conspiratorial undertakings to be revealed.

Through the practice of transparency activism, WikiLeaks has assumed a role designed to reveal these conspiracies. As Assange told Time in 2010, when deceptive organisations are put under public scrutiny, "they have one of two choices... [the first] is to reform in such a way that they can be proud of their endeavours, and proud to display them to the public... [the second] is to lock down internally and balkanize, and as a result, of course, cease to be as efficient, open and honest, or they can be closed conspiratorial and inefficient" (cited in Chua-Eoan 2010). Presumably, because a conspiracy can be "split" by reducing or "eliminating important communication" channels, WikiLeaks is designed to achieving such an end. As documents are leaked and secrets revealed, the capacity to conspire is reduced and hence the power of 
conspiratorial undertakings diluted. The hope is that an organisation like WikiLeaks is able to "carry us through the mire of politically distorted language, and into a position of clarity"; the eventual hope being that leaking will reveal insights that may inspire oppositional political actors towards "a course of ennobling, and effective action" (Assange 2006a:1). Consequently, through the vehicle of transparency activism, Assange's fundamental goal is to expose the secrets and goals of the powerful. To this end, WikiLeaks seeks to, first, dissolve conspiratorial undertakings by reducing conspiratorial capacity through transparency activism; and, second, to inspire widespread support for, and the expectation of, such transparency within the broader democratic community. WikiLeaks is thus based on the notion that "sufficient principled leaking" - the practice of transparency activism - will assist in bringing down secretive and oppressive governments and organisations that rely on obscuring reality from the general public (WikiLeaks 2011).

\section{Anarchy, Hackers and Cypherpunks}

It in part for these reasons that Assange has been labelled an anarchist and WikiLeaks described as an anarchist organisation. As we saw, the broad intention of these labels is to delegitimise the WikiLeaks project by invoking a negative and anti-social characterisation of anarchism (see Brooks 2010). This depiction was exemplified in a column in the Daily Mail, which argued that "[a]lthough Assange claims to be driven by the desire for freedom, his attitude - profoundly paranoid and politically anarchist - has more to do with his dysfunctional personal history than any political principle" (Amory 2010). Though Assange himself publicly rejects the anarchist label (see Assange 2010c), this is likely an instrumentally rational, defensive strategy, rather than a direct rejection of anarchical principles. Indeed, Manne (2011) suggests that the 
eschewing of an anarchical identity by both Assange and WikiLeaks is a conscious tactic designed to conceal the organisation's more radical goals.

Nonetheless, Assange's early experiences in the hacktivist culture reveals the emergence of a nascent and altruistic anarchist sensibility. In a book that was later attributed to the research of Assange, Underground, the principled 'golden rules' of hacking were made clear: "don't damage computer systems you break into (including crashing them); [and] don't change the information in those systems and share information" (Dreyfus 1997:77). Assange's early foray into hacking with the International Subversives' also revealed a personal coalescence with this principled outlook; along, once again, with an embrace of the hacktivist norm that that information should be shared and "everyone should have access to everything" (cited in Khatchadourian 2010).

The impact of Assange's early hacker influences is reinforced through his involvement with the "cypherpunks", a movement inclined towards an anti-statist political position known as "crypto-anarchism". Crypto-anarchism holds that anonymous communication, made possible through the free and global dissemination of public-key cryptography technology over the Internet, will allow for the eventual triumph of individual freedom over state-sanctioned violence and domination; and that developments in intellectual history and computer software are trending towards the realisation of emancipation (Hughes 1993, Levy 1996). This form of anarchism, however, is dominated by right-wing libertarians who champion Randian 'objectivism' and unrestrained capitalism (Manne 2011). Tim May, the most recognisable public representative of this trend within the cypherpunks, envisages an objectivist utopia where autonomous individuals only need deal with one another on a 
completely voluntary basis (May 1994). Though he holds that the inescapable and unrestricted expansion of cryptographic technologies will inevitably result in cryptoanarchist victory, until this time, May advocates such strategies as tax avoidance, the selling of military secrets and the development of "assassination markets" to keep state managers in line (Manne 2011). He also recognises that any crypto-anarchist future would necessarily result in the centralisation of technical control in a small number of technologically-proficient elites and that this small percentage will be the ones to prosper. Meanwhile, the rest - the masses, the "clueless $95 \% \ldots$ the unproductive, the halt and the lame" - would suffer in any future anarcho-capitalist utopia, but this would only be "just" (May cited in Manne 2011: 22)

Within this environment, Assange was a dissenter (see Manne 2011). Like many sympathetic to the (traditionally socialistic) principles of anarchism, he rejects 'anarcho-capitalism' as a misnomer. Assange staunchly denies the perceived 'virtues' of capitalism promoted by the libertarian figures so influential within the cypherpunk movement. Rejecting the possibility of any substantive connection between antistatism, capitalism and emancipatory praxis, Assange is particularly critical of the idea of laissez-faire capitalism, of the exploitative wage relationship that necessarily underpins it, and of the excessive power contemporary corporate entities exercise through the processes of neoliberal globalisation and the decision-making channels of the nation-states therein (see Harvey 2005: 19, Springer 2010: 544-546).

Despite these substantive differences, however, Assange concurs with the cypherpunks in two main areas: firstly, that the modern state's surveillance capabilities need be resisted, and, secondly, that absolute cryptographic freedom 
ought to be pursued to this end (Manne 2011). It is these Cypherpunk ideas that find expression in the praxis of WikiLeaks.

\section{WIKILEAKS AND ANARCHISM}

As noted earlier, anarchism is a complex and multifaceted ideology, but one which we have understood in particular ways in our conceptualisation of WikiLeaks. At the outset we identified the championing of an informational commons - committed to the free access to and exchange of information which an anarchical Internet renders possible - as a central component of WikiLeaks' anarchism. To this degree, the ends of individual freedom are to be found, in part at least, in the means of cyber technology utilised by WikiLeaks. Inspired by the altruistic, anarchical elements of hacktivist culture, the anti-statism of crypto-anarchism and utilising the anarchic infrastructure of the Internet and hacker software advances for the purposes of leaking, WikiLeaks seeks to make information free so that the power and privilege of governments and corporations dissolves and the "conspiratorial power" that it argues maintains their deceptions, disappears. Assange understands the defining human struggle not so much as 'left' against 'right' or an Enlightenment struggle of reason versus faith but, rather, as individual versus institution. He believes that "truth, creativity, love, and compassion are corrupted" by hierarchical institutions and "patronage networks" that warp the human spirit (cited in Katchadourian 2010). Hence, despite his 'scientific journalism', Assange does not seek to provide an 'impartial' account of events. Rather, his mission, and the purpose of WikiLeaks, is to reveal injustices and abuses of power by undermining the capacity of the powerful to keep their deceptions and ambitions secret. WikiLeaks' overall pledge is, in short, that transparency activism will act as a mechanism to undermine centralised power and subvert institutional hierarchy. Indeed, Assange suggested exactly this to potential 
partners of the WikiLeaks' project, claiming that the organisation "will provide a catalyst that will bring down governments through stealth everywhere" and could assist in unravelling regimes that maintain their authority through deceit and dishonesty (cited in Manne 2011:30). It is in this vein that WikiLeaks targets explicitly authoritarian regimes like China and Russia. However, the organisation also seeks to reveal "the immoral behaviour" and secrets of capitalist governments and monopolistic corporations, in the process "bring[ing] down... [organisations] that rely on concealing reality - including the US administration" (Assange cited in Katchadourian 2010).

WikiLeaks further reveals its anarchical character through its identification of corporate and institutional power as detrimental to the actualisation of human freedom. A brief analysis reveals that the collectivity of WikiLeaks views corporations as centralised authoritarian entities which utilise pervasive surveillance measures to regularly spy on their workers, and where economic efficiency and growth are continuously privileged over human liberty and equality (WikiLeaks 2011). Its critique of capitalism, and its explicit anti-statism, reveal an aversion, not just to particular hierarchical arrangements, but to the very notion of externally imposed authority and hierarchy (see Proudhon 2007 [1840]). WikiLeaks' radical pursuit of transparency activism thus highlights its anarchical commitment to the decentralisation of power and information in the service of a more open democracy dedicated to the pursuit of individual freedom and non-hierarchical social organisation.

\section{Means and Ends: Wikileaks, Hierarchy and Authoritarianism}


Despite this subscription to anarchical principles and ambitions, WikiLeaks, particularly as mediated through its 'editor-in-chief', is not without contradiction. Thus far, our discussion has focused on Assange as a major driver of the WikiLeaks ambition; however, a brief exploration of WikiLeaks' current organisational tensions reveals some inconsistencies with the anarchical story we have thus far outlined, particularly in what it reveals about a key feature of an anarchist politics: the correspondence between means and ends. For social change to be successful, anarchism holds that the organisational forms that will replace the hierarchical constructions, like capitalism and the state, need to be cultivated alongside any direct offensive against the existing institutions of domination (Gordon 2007b:40). A movement like WikiLeaks, whose ambition is to transform the social order, "must necessarily anticipate the ways and means of the hoped-for new society" (Carter and Morland 2004:79). This pursuit of a 'prefigurative' politics is a necessary characteristic of any anarchistic praxis aimed at producing social change for, as Bookchin argues, "the very process of building an anarchist movement from below is viewed as the process of consociation, self-activity and self-management that must ultimately yield the revolutionary self that can act upon, change and manage an authentic society" (Bookchin 1996:29). If, as Assange claims, hierarchies and 'patronage' networks are what warp the autonomous human spirit, then it must be assumed that this entails "self-activity" alert to authoritarian developments within his own organisation. Paradoxically, these developments risk WikiLeaks replicating aspects of the social order it seeks to transform.

Despite the anarchical aims of WikiLeaks, recent concerns have emerged over its own increasingly hierarchical, centralised and secretive praxis; the result, it is claimed, of the increasingly megalomaniacal character of Julian Assange himself 
(Domscheit-Berg 2011:216-230). As opposed to its open-source, wiki-based foundations, whereby the organisation sought to rely on user modification and contribution, WikiLeaks has consciously moved towards a more closed system where decisions regarding content are made exclusively by people within the organisation itself and the analytical work done by professionals brought in for that sole purpose. This move was justified on the grounds that the original WikiLeaks' vision - that online citizens would voluntarily opt to scrutinise leaked documents and on discovering their implications would demand major socio-political change - had failed in practice. The expected uptake of leaked material by the Internet's online citizens never emerged. Consequently, vast quantities of material were going to waste. In the hope of renewing public attention to leaked documents, WikiLeaks staff thus began restricting the flow of source material and selecting what was to be released (Assange 2010d, Leigh and Harding 2011:60). This process vested and centralised significant editorial powers in the hands of a small number of actors, Assange in particular (Domscheit-Berg 2011:228-229; Taylor 2010). Former spokesperson and effective 'number two', Daniel Domscheit-Berg claims that this development represented, essentially, the repudiation of the anarchical principles that had originally inspired WikiLeaks' formation:

I tried... to push for [equal treatment of less-popular material], but Julian Assange reacted to any criticism with the allegation that I was disobedient to him and disloyal to the project... [H]e suspended me-- acting as the prosecutor, judge and hangman in one person. Since then, for example, I have had no access to my WikiLeaks mail. So a lot of work is just sitting and other helpers are being blocked. I know that no one in our core team agreed with the move. But that doesn't seem to matter. WikiLeaks has a structural problem. I no 
longer want to take responsibility for it, and that's why I am leaving the project (cited in Blodget 2010).

In Inside WikiLeaks, Domscheit-Berg goes further, arguing that Assange's singleminded pursuit of the WikiLeaks vision ended up replicating, rather than challenging, the hierarchies it opposes. In the process, WikiLeaks violated the core values and principles central to its foundations - principles that Domscheit-Berg argues were central to inspiring the WikiLeaks project and its commitment to building a more equitable and less hierarchical social order:

In the world we dreamed of, there would be no more bosses or hierarchies, and no one could achieve power by withholding from the other the knowledge needed to act as an equal player. That was the idea for which we fought. It was the project that we started together and watched grow with enormous pride (Domscheit-Berg 2011:4)

In short, the hierarchy and centralisation that was purportedly the target of WikiLeaks' radical ambitions turned in on itself, significantly compromising these pursuits and marginalising its animating values. For Domscheit-Berg (2011:270), WikiLeaks has become no more than a bastion of political struggle shaped by Assange's political agenda and personal struggles.

\section{CONCLUSION}

This paper has identified some important synergies between anarchist principles and practices and the values and ambitions of WikiLeaks. To this degree, WikiLeaks critics may be right in labelling it anarchist, even as the intent of such labelling is usually to disparage the organisation. Governments around the world consistently 
imply that something revolutionary and 'anarchic' forms the core of the organisation's aims and intellectual identity. While both Assange and WikiLeaks have openly rejected revolutionary and anarchical labels, analysis of WikiLeaks' formative ideas reveals a much closer - if muddled - relationship with revolutionary praxis than either would openly admit. Certainly, WikiLeaks resonates strong anarchical impulses and is motivated by some of the core analyses and ideals of anarchist ideology. This is not to suggest that WikiLeaks is - or was - a 'card-carrying' doctrinal anarchist organisation, which is in keeping with Assange's own rejection of the label anarchist, as well as in keeping with some of the recent scholarship on contemporary anarchism which distinguishes between anarchism per se and the significant influence of anarchist values in oppositional politics (see Epstein 2001).

As explored above, the outward liberal reformism apparent in the propagation of WikiLeaks and its advocation of transparency activism appears in many ways as window-dressing to the revolutionary aims that have influenced Assange and the formation of WikiLeaks. Though decidedly reformist in its conceptualisation, the notion of transparency activism is itself central to the revolutionary ideas and aims that form the core of WikiLeaks: that principled leaking will first, invoke mass resistance to the 'conspiratorial' tendencies inherent in both statist and capitalist modes of organisation today; and second, eventually destroy the capacity for power elites to maintain conspiracies by cutting the closed communicative channels necessary in their maintenance. In doing this, WikiLeaks seeks to realise the anarchist goal of a post-capitalist society organised along non-hierarchical and directly democratic lines, and where, as Assange hopes, truth, creativity and love are able to emerge in more authentic and spontaneous forms. Yet, problematically, without addressing the way in which WikiLeaks - particularly its central figure, Julian 
Assange - is replicating the hierarchical organisational forms of capitalist society, such a revolutionary promise may never be realised.

Two paradoxes help illustrate the problematic character of WikiLeaks' anarchical experiment. First, in some interesting ways, the experience of WikiLeaks particularly under Assange - mirrors the trajectory of the Internet's early promise. As we saw, the Internet emerged within a libertarian environment that promised the gifting of an informational and democratic commons. This potential was quickly corroded by commercial and associated state-based actors intent on utilising its enormous scope for other purposes. To this end an earlier libertarian incarnation of cyberspace, particularly in its capacity to create a public space devoted to radical democracy (Crang 2000), was quickly displaced by increasingly centralised, censored and authoritarian forms. Elements of Assange's WikiLeaks project threaten a similar trajectory. Second, while the new technologies have enabled WikiLeaks' 'hacktivism' and the 'liberation' of information that sits at its core, the impact of this leaking is at the same time significantly circumscribed by the uneven scope and reach of these very same technologies. As we saw, the aims of WikiLeaks' transparency activism were essentially twofold: first, to uproot and expose the conspiracies of the powerful; and second, to inspire a principled activist reaction from an appalled public. Instead, the response by the well resourced publics able to access the leaks - publics who increasingly consume the new technologies for a wide range of non-political reasons was, by most measures, underwhelming; while those whom the content of the leaks most affected (for example, in Iraq or Afghanistan) had only limited or no access to them. This touches on a key point explored earlier: that while the Internet opens up democratic and anarchical potentialities through the development of a better informed and more engaged public, the realisation of these potentialities is reliant upon the 
material manifestation of radical action by this public on the ground. The irony here is that while the Internet's tools made the leaks possible, its spatially uneven geographic distribution and consumption (rooted itself in the materiality of social relations) undercut their effect. As Reid-Henry (2011) comments: "In today's informational world, we need more than just the truth to save us it seems".

Overall, our analysis of the WikiLeaks project finds that it is garnering some success in confronting and delegitimising the current social arrangements of powerful statist institutions. Informed by an anarchist sensibility, and utilising hacktivist tools, WikiLeaks' transparency activism directly confronts institutionalised power by seeking the creation of an informational commons in the service of a more transparent, democratic world. However, WikiLeaks itself seems to be less successful in providing an anarchistic prefigurative alternative to these prevailing social arrangements. Such an alternative would see the organisation "employing a strategy that is an embryonic representation of" any future liberated society (Carter and Morland 2004:79), rather than replicating some of those very organisational arrangements that it so roundly condemns. Reid-Henry (2011) observes that, "the way in which one unmasks the truth that power conceals is as important as, or more important than, the fact of unmasking itself'. As we saw, it is on this count that critics sympathetic to WikiLeaks' aims claim that the anarchical project is failing. Paradoxically, and despite the view of its mainstream detractors, WikiLeaks' continued legitimacy and impact may thus depend on the strengthening, rather than the dilution, of its anarchical values. 


\section{REFERENCES}

Abbate J (1999) Inventing the Internet. Cambridge: MIT Press.

Amory E H (2010) Paranoid, Anarchic... Is Wikileaks Boss a force for Good or Chaos?. The Daily Mail Online. 27 July, 2010.

<http://www.dailymail.co.uk/news/article-1297917/Is-Wikileaks-boss-JulianAssange-force-good-chaos.html> (last accessed 27 March, 2011).

Assange J (2006a) State and Terrorist Conspiracies. 10 November, 2006. <http://cryptome.org/0002/ja-conspiracies.pdf> (last accessed 11 March, 2011).

Assange J (2006b) Conspiracy as Governance. 3 December, 2006. <http://cryptome.org/0002/ja-conspiracies.pdf> (last accessed 11 March, 2011).

Assange J (2010a) Don't Shoot the Messenger for Revealing Uncomfortable Truths. The Australian. 8 December, 2010. <http://www.theaustralian.com.au/indepth/wikileaks/dont-shoot-messenger-for-revealing-uncomfortable-truths/storyfn775xjq-1225967241332> (last accessed 23 March, 2011).

Assange J (2010b) Julian Assange on Wikileaks, War and Resisting Government Crackdown. Democracy Now!. 31 December, 2010. <http://www.democracynow.org/2010/12/31/julian_assange_on_wikileaks_war_an d> (last accessed 23 March, 2011).

Assange J (2010c) Defending the Leaks: Q\&A With Wikileaks' Julian Assange. Time Magazine. 27 July, 2010.

<http://www.time.com/time/world/article/0,8599,2006789-1,00.html> (last accessed 20 March, 2011).

Assange J (2010d) TIME's Julian Assange Interview: Full Transcript/Audio. Time Magazine. 1 December, 2010.

<http://www.time.com/time/world/article/0,8599,2034040-1,00.html> (last accessed 7 April, 2011). 
Barbrook R (1998) The Hi-Tech Gift Economy. First Monday 3(12). $<$ http://www.firstmonday.org/htbin/cgiwrap/bin/ojs/index.php/fm/article/view/631/ 552> (last accessed 14 April, 2011).

Bey H (2003) TAZ The Temporary Autonomous Zone, Ontological Anarchy, Poetic Terrorism. $2^{\text {nd }}$ edition. New York: Autonomedia.

Blodget H (2010) WikiLeaks Spokesman Quits, Blasts Founder Julian Assange As Paranoid Control Freak, Admits To Using Fake Name. San Francisco Chronicle. 28 September, 2010. <http://www.sfgate.com/cgibin/article.cgi?f=/g/a/2010/09/28/businessinsider-wikileaks-spokesmanquits.DTL> (last accessed 17 April, 2011).

Bookchin M (1991) The Ecology of Freedom: The Emergence and Dissolution of Hierarchy. Montreal: Black Rose Books.

Bookchin M (1996) 'Anarchism Past and Present' in H J Ehrlich (ed) Reinventing Anarchy, Again. Edinburgh: AK Press.

Breitbart M (2009) Anarchism/Anarchist Geography. International Encyclopedia of Human Geography (pp 108-115).

Brooks D (2010) The Fragile Community. The New York Times. 29 November, 2010. <http://www.nytimes.com/2010/11/30/opinion/30brooks.html?_r=2\&hp> (last accessed 17 April, 2011).

CBC News (2007) Website Wants to Take Whistleblowing Online. CBC News. 11 January, 2007. <http://www.cbc.ca/news/story/2007/01/11/wikileaks-whistle.html $>$ (last accessed 7 April, 2011).

Carter J and Morland D (2004) Anti-Capitalism: Are We All Anarchists Now?. in J Carter and D Morland (eds) Anti-Capitalist Britain. Gretton: New Clarion Press.

Castells M (2001) The Internet Galaxy: Reflections on the Internet, Business and Society. Oxford: Oxford University Press.

Christensen C (2011) Twitter Revolutions? Addressing Social Media and Dissent. The Communication Review 14(3):155-157. 
Chua-Eoan H (2010) TIME Interview: Assange on Secrecy, China and WikiLeaks' Growth. Time Magazine. 1 December, 2010.

<http://www.time.com/time/world/article/0,8599,2033887,00.html> (last accessed 7 April, 2011).

Crampton J W (2003) The Political Mapping of Cyberspace. Chicago: University of Chicago Press.

Crang M (2000) Public Space, Urban Space and Electronic Space: Would the Real City Please Stand Up? Urban Studies 37:307-317.

Curran G (2006) $21^{\text {st }}$ Century Dissent: Anarchism, Anti-globalisation and Environmentalism. London and New York: Palgrave Macmillan.

Dean J (2003) Why the Net is not a Public Sphere. Constellations 10:95-112.

Diani M (2001) Social Movement Networks: Virtual and Real. In F Webster (ed) Culture and Politics in the Information Age. London: Routledge (pp 117-141).

Domscheit-Berg D (2011) Inside WikiLeaks. J Chase (Trans). Melbourne: Scribe.

Dreyfus S (1997) Underground: Tales of Hacking, Madness and Obsession on the Electronic Frontier, With Research by Julian Assange. Kew: Mandarin.

Epstein, B (2001) Anarchism and the Anti-Globalization Movement. Monthly Review 53(4). <https://www.monthlyreview.org/0901epstein.htm> (last accessed 17 July, 2011).

Foucault M (1980) Power/Knowledge. New York: Pantheon.

Free Software Foundation (n.d.) Free Software Foundation <www.fsf.org/> (last accessed 14 August 2006).

Gellman B (2011) Julian Assange. Time Magazine.

<http:www.time.com/time/sepcials/packages/printout/0,29239,2036683_2037118_ 203> (last accessed 22 March, 2011). 
Gilbert M, Masucci M. Homko C and Bove A (2008) Theorizing the Digital Divide. Geoforum 39:912-925.

Gordon U (2007a) Anarchy Alive! Sydney: Pluto Press.

Gordon U (2007b) Anarchism Reloaded. Journal of Political Ideologies 12(1):29-48.

Gordon U (2009) Anarchism and the Politics of Technology. The Journal of Labor and Society 12:489-503.

Graeber D (2002) The New Anarchists. New Left Review 13(6):61-73.

Graeber D (2004) Fragments of an Anarchist Anthropology. Chicago: Prickly Paradigm Press.

Green Anarchy Collective (2004) .What is Green Anarchy? An Introduction to AntiCivilization Anarchist Thought and Practice. Back to Basics 4(17):35-41.

Guerin D (1970) Anarchism: From Theory to Practice. New York: Monthly Review Press.

Harvey, D (2005) A Brief History of Neoliberalism. Oxford: Oxford University Press.

Hughes E (1993) A Cypherpunk's Manifesto.

<http://www.activism.net/cypherpunk/manifesto.html> (last accessed 20 April, 2011).

IndianExpress.com (2010) WikiLeaks Founder Julian Assange 'Anarchist', Not Journalist, 3 December < http://www.indianexpress.com/news/wikileaks-founderjulian-assange-anarchist/719895/> (last accessed 12 September, 2011).

Jordan T (2002) Activism! Direct Action, Hacktivism and the Future of Society. London: Reaktion.

Jordan T (2008) Hacking. Cambridge: Polity Press.

Khatchadourian R (2010) No Secrets: Julian Assange's Mission for Total Transparency. The New Yorker. 7 June, 2010. 
<http://www.newyorker.com/reporting/2010/06/07/100607fa_fact_khatchadourian ?currentPage $=$ all $>($ last accessed 12 May, 2011).

Kinna R (2005) Anarchism. Oxford: OneWorld Publications.

Leigh D and Harding L (2011) WikiLeaks: Inside Julian Assange's War on Secrecy. London: Guardian Books.

Levy S (1996) Crypto Rebels in P Ludlow (ed) High Noon on the Electronic Frontier: Conceptual Issues in Cyberspace. Cambridge: MIT Press.

Lukes, S (2005) Power: a Radical View, Second Edition. New York: Palgrave Macmillan.

Manne R (2011) The Cypherpunk Revolutionary: Robert Manne on Julian Assange. The Monthly. March, 2011: 16-35.

Marshall P (1993) Demanding the Impossible: A History of Anarchism. London: Fontana Press.

May T C (1994) The Cyphernomicon: Chypherpunks FAQ and More, Version 0.666. <http://www.cypherpunks.to/faq/cyphernomicron/cyphernomicon.html\#TOC> (last accessed 4 May, 2011).

Meek D (2011) Youtube and Social Movements: A Phenonomenological Analysis of Participation, Events and Cyberplace. Antipode Early View (Online version) 21 September, 2011.

Mitchell D (2003) The Right to the City: Social Justice and the Fight for Public Space. New York: Guilford

Naughton J (2000) A Brief History of the Future: From Radio Days to Internet Years in a Lifetime. Woodstock and New York: The Overlook Press.

Pickerill J (2003) Cyberprotest: Environmental Activism On-line. Manchester: Manchester University Press. 
Pilger J (2011) Wikileaks Defies the 'War on Hi-Tech Terror'. New Statesman. 19 January, 2011. <http://www.newstatesman.com/media/2011/01/assange-pilgerwikileaks> (last accessed 21 May, 2011).

Proudhon P J (2007 [1840]) What is Property? D R Kelley and B G Smith (eds). New York: Cambridge University Press.

Reid-Henry S M (2011) On Zizek on WikiLeaks: Two Figures and a Point of Critique. Antipode Early View (Online version) 22 August, 2011.

Rocker R (1938) Anarcho-Syndicalism. London: Phoenix Press.

Sassen S (2002) Towards a Sociology of Information Technology. Current Sociology 50(3):365-388.

Schouten P (2008) David Harvey on the Geography of Capitalism, Understanding Cities as Polities and Shifting Imperialisms. Theory Talks \#20 $<$ http://www.theorytalks.org/2008/10/theory-talk-20-david-harvey.html (last accessed 12 September, 2011).

Spar D (2001) Ruling the Waves: Cycles of Discovery, Chaos, and Wealth, from the Compass to the Internet. New York: Harcourt.

Springer S (2011) Public Space as Emancipation: Meditations on Anarchism, Radical Democracy, Neoliberalism and Violence. Antipode 43(2):525-562.

Taylor J (2010) Secret War at the Heart of Wikileaks. The Independent. 25 October, 2010.

Warf B (2001) Segueways into Cyberspace: Multiple Geographies of the Digital Divide. Environment and Planning B 28:3-19.

Wainwright J and Kim S-J (2008) Battles in Seattle Redux: Transnational Resistance to a Neoliberal Trade Agreement. Antipode 40:513-534.

Welch D (2011) Assange Permeates Pages he was Determined to Block. Sydney Morning Herald. 15-16 October, 2011. 
Wikileaks (2011) 'About: What is Wikileaks?', Wikileaks Website.

$<$ http://213.251.145.96/About.html> (last accessed 27 June, 2011).

Williams J (2007) The Geography of Accumulation: An Interview with David Harvey. The Minnesota Review 69.

http://www.theminnesotareview.org/journal/ns69/interview_harvey.shtml (last accessed 3 December, 2011)

Winner L (1985) The Whale and the Reactor: A Search for Limits in an Age of High Technology. Chicago: Chicago University Press.

Zerzan J (1994) Future Primitive. New York: Autonomedia.

Zook, M and Graham, M (2007) The Creative Reconstruction of the Internet: Google and the Privatization of Cyberspace and DigiPlace. Geoforum 38(6):1322-1343. 